\title{
Failure to Intervene on Thyroid Cancer: A Study of the National Cancer Database
}

\author{
Megan K Applewhite ${ }^{1}$, Michael G White ${ }^{2}$, Edwin L Kaplan ${ }^{3}$, Peter Angelos ${ }^{4}$, Raymon H Grogan ${ }^{5}$
}

\begin{abstract}
Background: The concept of failure to intervene (FTI) was introduced in the context of pancreatic cancer patients with an operable malignancy, who did not undergo surgery. Here, we investigate FTI in the thyroid cancer population. We define patients with operable thyroid cancer with $\mathrm{FTI}$, define risk factors for $\mathrm{FTI}$, and evaluate overall survival.

Materials and methods: Patients with histologic codes corresponding to papillary, follicular, or medullary thyroid cancer in the National Cancer Database were identified and divided into three categories: "FTI," "No Surgery: Intentional (NSI)," and "Surgery." Risk factors for FTI were studied using univariate and multivariate logistic regression. Survival differences were studied using Cox Hazards modeling.

Results: Of those studied, 294,088(96.6\%) underwent surgery, 8,939(2.9\%) were NSI, and 1,579(0.5\%) were FTI. Those in the FTI group were older than the surgery group, more likely to be male, black, have Medicare, or be uninsured [all $p<0.001]$. Independent risk factors for FTI were: lack of insurance [OR $=3.79(2.98-4.82), p<0.001]$, stage IVc disease [OR = $3.98(3.11-5.09), p<0.001]$, and Asian [OR $=1.98(1.56-2.52), p<0.001]$ or Black race $[\mathrm{OR}=2.08(1.73-2.50), p<0.001]$. There was a significant overall survival advantage for the surgery group as compared to the NSI [Cox Hazard Ratio $=3.795 \% \mathrm{Cl}(3.3-4.1), p<0.001$ ] and FTI groups [Cox Hazard Ratio $=7.095 \% \mathrm{Cl}(6.7-7.2), p<0.001]$.

Conclusion: Nearly $97 \%$ of thyroid cancer patients in the United States undergo surgical resection. Not having a surgical resection corresponds to a decrease in survival. Non-white race and lack of insurance were risk factors for FTI. Further work needs to be done to identify and appropriately treat this subset of patients who would benefit from resection.

Keywords: Disparity, Failure to intervene, Insurance, NCDB, Race, Thyroid Cancer, Travel.

World Journal of Endocrine Surgery (2021): 10.5005/jp-journals-10002-1405
\end{abstract}

\section{INTRODUCTION}

Failure to intervene ( $\mathrm{FTI})$ is a concept that was first used to describe the patient population that has resectable pancreatic cancer, but does not undergo surgery, in spite of proven superior survival with pancreatectomy. ${ }^{1}$ Authors concluded that FTI in these patients likely occurs because of the overall poor prognosis of patients with pancreatic cancer, with an average 5-year survival of less than $5 \% .^{2}$ Addressing and minimizing inconsistencies in cancer care delivery has become a priority on the national level. FTI when clinical practice guidelines dictate superior outcomes with pointed intervention has generated quality improvement efforts by the National Quality Forum at the request of the Department of Health and Human Services. In 2012, the National Quality Forum endorsed cancer care performance measures that focused on multiple cancer types, including: melanoma, prostate, lung, breast, and colon as well as palliative care in an effort to minimize disparities in cancer treatment. ${ }^{3}$

The racial and socioeconomic disparities in administration of cancer care have been well established in many malignancies including thyroid cancer. What has not been studied is what happens in the long term to thyroid cancer patients who do not undergo surgical intervention when it is indicated. Naturally, some individuals will decline an operation or decided against it in favor of nonoperative active surveillance; this is the case with those who have significant comorbidities and those who refuse surgery. It is those patients with thyroid cancer who have not intentionally declined or decided against surgery, but yet who still do not have an operation, that is a poorly understood population. Who these people are, and their postdiagnosis survival is yet to be defined. Theoretically, as the prognosis of most thyroid cancer is excellent,
${ }^{1}$ Department of Surgery, Albany Medical Center, Albany, New York, United States

${ }^{2}$ Department of Surgery, MD Anderson Cancer Center, Houston, Texas, United States

${ }^{3,4}$ Department of Surgery, University of Chicago, Chicago, Illinois, United States

${ }^{5}$ Department of Surgery, Baylor College of Medicine, Houston, Texas, United States

Corresponding Author: Megan K Applewhite, Department of Surgery, Albany Medical Center, Albany, New York, United States, Phone: +18572057446, e-mail: applewm@amc.edu

How to cite this article: Applewhite MK, White MG, Kaplan EL, et al. Failure to Intervene on Thyroid Cancer: A Study of the National Cancer Database. World J Endoc Surg 2021;13(2):47-52.

Source of support: Nil

Conflict of interest: None

these people may not have a difference in overall survival, however, this is not known.

Utilizing the National Cancer Database (NCDB), we aim to compare three groups of thyroid cancer patients: (1) those who underwent surgery, (2) those who did not have surgery for a specific reason, and (3) those who had an indication for surgery but did not undergo an operation. This third group will be referred to as "failure to intervene" (FTI), as the data would suggest they had an indication for surgery, and no reason was provided for why it did not happen. Here, we aim to identify and discuss differences in demographics, pathology, and survival in the FTI group. We hypothesize that these patients are less likely to have private 
insurance and more likely to be made up of patients from zip codes with lower overall income. Additionally, we anticipate that the FTI group will have lower overall survival than the group that underwent surgery. Making ourselves aware of the FTI population will allow us to be more likely to identify them in clinic visits, and potentially will allow us to make a concerted effort to manage them per the standard of care with thyroidectomy and potentially improve overall survival.

\section{Materials and Methods}

All patients in the NCDB with histology codes corresponding to papillary thyroid carcinoma $(8,260,8,343,8,341,8,050,8,342,8,343$, $8,344,8,504)$, follicular thyroid carcinoma $(8,330,8,331,8,332,8,335)$, Hurthle cell carcinoma $(8,290)$, and medullary thyroid carcinoma $(8,345,8,346,8,347,8,510)$ were selected out and included for study.

These patients were divided into three groups for analysis. The first group underwent surgery for their thyroid cancer. They are referred to as the "surgery" group. The second group did not have surgery, but there was a specific reason listed as to why they did not have surgery. Possible reasons were: surgery not part of planned treatment, surgery contraindicated due to risk factors, and patient death prior to operation. This is referred to as "no surgery: intentional" (NSI) group. Finally, the third group is the FTI group. These patients had indication for thyroidectomy, but did not undergo surgery, and had no reason listed in the record as to why they did not receive appropriate treatment. Income of patients was determined by zip code.

Demographic differences between groups were studied using Student's t-test and analysis of variance analyses. Risk for inclusion into the FTI group was modeled using univariable and multivariable logistic regression. Multivariable models were inclusive of all factors found to be significant on univariable analysis. Survival differences between groups were studied using Cox-hazards ratios. Significance was defined as a $p$-value less than 0.05. All analysis was performed using STATA Version 13 (College Station, TX). ${ }^{4}$

\section{Results}

Of the 304,605 patients studied, 294,088 (96.6\%) underwent operative intervention, 8,939 (2.9\%) were in the NSI group, and $1,579(0.5 \%)$ were in the FTI group (Table 1). Demographic differences by group are summarized in Table 2. Patients in the NSI group were older and more likely to be male compared

Table 1: Reasons for not operating

\begin{tabular}{lc}
\hline & $n(\%)$ \\
\hline $\begin{array}{l}\text { Surgical intervention } \\
\text { Surgery of the primary site was performed }\end{array}$ & 294,088 \\
& $(96.6)$ \\
No surgery: intentional & $8,225(2.7)$ \\
$\begin{array}{l}\text { Surgery was not part of planned first course } \\
\text { treatment }\end{array}$ & $601(0.2)$ \\
$\begin{array}{l}\text { Surgery was not recommended/performed, } \\
\text { contraindicated due to patient risk factors }\end{array}$ & $113(0.04)$ \\
$\begin{array}{l}\text { Surgery was not performed because the patient died } \\
\text { prior to planned or recommended surgery }\end{array}$ & \\
$\begin{array}{l}\text { Failure to intervene } \\
\text { Surgery was recommended by physician but not per- }\end{array}$ & $454(0.2)$ \\
formed, No reason was noted in patient record \\
$\begin{array}{l}\text { Surgery was recommended but was refused by the } \\
\text { patient, patient's family member or guardian }\end{array}$ & $527(0.2)$ \\
$\begin{array}{l}\text { Surgery was recommended, but unknown if } \\
\text { performed }\end{array}$ & $598(0.2)$ \\
\hline
\end{tabular}

Table 2: Demographics

\begin{tabular}{|c|c|c|c|c|}
\hline & $\begin{array}{l}\text { Surgical intervention } \\
\qquad(n=294,088)\end{array}$ & $\begin{array}{l}\text { No surgery: intentional } \\
\qquad(n=8,939)\end{array}$ & $\begin{array}{l}\text { Failure to intervene } \\
\qquad(n=1,579)\end{array}$ & $p$ \\
\hline Age & $49.9 \pm 15.4$ & $61.8 \pm 18.1$ & $51.0 \pm 19.3$ & $<0.001$ \\
\hline Sex (n, \% male) & 70,015 (23.8\%) & 3,301 (36.9\%) & $506(32.1 \%)$ & $<0.001$ \\
\hline Median income & & & & $<0.001$ \\
\hline$<\$ 38,000$ & 38,496 (13.2\%) & 1,435 (16.4\%) & $244(15.8)$ & \\
\hline$\$ 38,000-\$ 47,999$ & $58,929(20.3 \%)$ & 1,914 (21.9\%) & $280(18.2 \%)$ & \\
\hline$\$ 48,000-\$ 62,999$ & 77,447 (26.6\%) & $2,282(26.2 \%)$ & $427(27.7 \%)$ & \\
\hline$\geq \$ 63,000$ & 116,124 (39.9\%) & 3,096 (35.5\%) & $592(38.4 \%)$ & \\
\hline Insurance status & & & & $<0.001$ \\
\hline Not insured & $8,078(2.8 \%)$ & 405 (4.5\%) & $127(8.0 \%)$ & \\
\hline Private & 204,042 (69.4\%) & $3,752(42.0 \%)$ & $682(43.2 \%)$ & \\
\hline Medicaid & $16,660(5.7 \%)$ & $587(6.6 \%)$ & $122(7.7 \%)$ & \\
\hline Medicare & $55,558(18.9 \%)$ & 3,815 (42.7\%) & $551(34.9 \%)$ & \\
\hline Other government & 3,587 (1.2\%) & $100(1.1 \%)$ & $20(1.3 \%)$ & \\
\hline Unknown & $6,162(2.1 \%)$ & $280(3.2 \%)$ & 77 (4.9\%) & \\
\hline Race & & & & $<0.001$ \\
\hline White & 214,195 (72.8\%) & 6,128 (68.6\%) & $955(60.5 \%)$ & \\
\hline
\end{tabular}




\begin{tabular}{|c|c|c|c|c|}
\hline & $\begin{array}{l}\text { Surgical intervention } \\
\qquad(n=294,088)\end{array}$ & $\begin{array}{l}\text { No surgery: intentional } \\
\quad(n=8,939)\end{array}$ & $\begin{array}{l}\text { Failure to intervene } \\
\qquad(n=1,579)\end{array}$ & $p$ \\
\hline Black & $20,225(6.9 \%)$ & 794 (8.9\%) & $194(12.3 \%)$ & \\
\hline Asian & $12,226(4.2 \%)$ & 412 (4.6\%) & 115 (7.3\%) & \\
\hline Hispanic & $36,734(12.5 \%)$ & $1,200(13.4 \%)$ & $236(15.0 \%)$ & \\
\hline Other & $10,707(3.6 \%)$ & 405 (4.5\%) & $79(5.0 \%)$ & \\
\hline$\%$ No HSD & & & & $<0.001$ \\
\hline$\geq 21 \%$ & $42,432(14.6 \%)$ & $1,654(18.9 \%)$ & $273(17.7 \%)$ & \\
\hline $13-21 \%$ & $66,166(22.7 \%)$ & $2,162(24.8 \%)$ & 345 (22.3\%) & \\
\hline $7-12.9 \%$ & $96,319(33.1 \%)$ & $2,728(31.2 \%)$ & $481(31.2 \%)$ & \\
\hline$<7 \%$ & $86,213(29.6 \%)$ & $2,189(25.1 \%)$ & $445(28.8 \%)$ & \\
\hline Facility type & & & & $<0.001$ \\
\hline Community Cancer Program & $15,856(7.3 \%)$ & $823(10.6 \%)$ & $171(13.6)$ & \\
\hline $\begin{array}{l}\text { Comprehensive Community } \\
\text { Cancer Program }\end{array}$ & $94,320(43.7 \%)$ & $3,480(44.9 \%)$ & $476(37.8 \%)$ & \\
\hline Academic Research Program & $89,203(41.3 \%)$ & $2,984(38.5 \%)$ & $545(43.3 \%)$ & \\
\hline $\begin{array}{l}\text { Integrated Network Cancer } \\
\text { Program }\end{array}$ & $16,481(7.6 \%)$ & $464(6.0 \%)$ & $67(5.3 \%)$ & \\
\hline Stage (TNM) & & & & $<0.001$ \\
\hline I & $122,526(41.7 \%)$ & $1,675(18.8 \%)$ & $448(28.4 \%)$ & \\
\hline II & $21,125(7.2 \%)$ & $471(5.3 \%)$ & $123(7.8 \%)$ & \\
\hline III & $16,150(5.5 \%)$ & $238(2.7 \%)$ & $74(4.7 \%)$ & \\
\hline IV & $823(0.3 \%)$ & $422(4.7 \%)$ & $23(1.5 \%)$ & \\
\hline IVa & $6,240(2.1 \%)$ & $577(6.5 \%)$ & $86(5.5 \%)$ & \\
\hline IVb & $858(0.3 \%)$ & $607(6.8 \%)$ & $40(2.5 \%)$ & \\
\hline IVc & $2,028(0.7 \%)$ & $1,647(18.5 \%)$ & $113(7.2 \%)$ & \\
\hline NR & $124,311(42.3 \%)$ & $3,292(36.7 \%)$ & $670(42.5 \%)$ & \\
\hline Histology & & & & $<0.001$ \\
\hline PTC & $265,922(90.4 \%)$ & $7,844(87.8 \%)$ & $1,422(90.1 \%)$ & \\
\hline $\mathrm{HCC}$ & $7,279(2.5 \%)$ & $230(2.6 \%)$ & $39(2.5 \%)$ & \\
\hline FTC & $15,666(5.3 \%)$ & $504(5.6 \%)$ & $84(5.3 \%)$ & \\
\hline MTC & $5,220(1.8 \%)$ & $361(4.0 \%)$ & $31(2.2 \%)$ & \\
\hline Charlson-Deyo score & & & & $<0.001$ \\
\hline 0 & $248,918(84.6 \%)$ & $7,251(81.1 \%)$ & $1,341(84.9 \%)$ & \\
\hline 1 & $37,805(12.9 \%)$ & $1,161(13.0 \%)$ & $158(10.0 \%)$ & \\
\hline 2 & $7,364(2.5 \%)$ & $527(5.9 \%)$ & $80(5.1 \%)$ & \\
\hline Procedures per year per facility & $71.0 \pm 72.6$ & $58.0 \pm 71.7$ & $59.1 \pm 68.7$ & $<0.001$ \\
\hline
\end{tabular}

to those in the surgery and FTI groups, who had similar ages and gender ratios to one another. The percentage of patients undergoing surgical intervention were significantly more likely to have private insurance, while those in whom surgery was not performed (both NSI and $\mathrm{FTI}$ ) were more likely to have Medicare and be uninsured. Rates of FTI by race demonstrate a larger percentage of white patients received a surgical intervention, while black patients were less likely to be NSI and had were over-represented in the FTI group. Those in the NSI group had a higher Charlson-Deyo score and were less likely to have suspected papillary histology.
In examining risk factors for inclusion in the FTI group, male sex on multivariable analysis [OR $=1.2795 \% \mathrm{Cl}(1.12-1.24)$, $p<0.001]$ was a risk factor. Neither education, nor income showed a significant effect on likelihood of being in the FTI group. Race showed a significant effect with every racial identity other than white being a risk factor for FTI. While a diagnosis of papillary thyroid carcinoma was protective $[\mathrm{OR}=0.8195 \% \mathrm{Cl}(0.70-0.93)$, $p=0.005]$. Comorbidities as measured by Charlson-Deyo score of 1 were protective $[\mathrm{OR}=0.6495 \% \mathrm{Cl}(0.54-0.77), p<0.001]$ while a score of 2 failed to show a significant effect. Facility type played a significant role on both univariate and multivariate analysis with 
Table 3: Risk factors for failure to intervene

\begin{tabular}{|c|c|c|c|c|}
\hline & Univariate & $p$ & Multivariate & $p$ \\
\hline Age & $1.03(1.02-1.03)$ & $<0.001$ & $1.04(1.03-1.04)$ & $<0.001$ \\
\hline Sex (male) & $1.47(1.32-1.64)$ & $<0.001$ & $1.27(1.12-1.24)$ & $<0.001$ \\
\hline \multicolumn{5}{|l|}{ Median income } \\
\hline$<\$ 38,000$ & REF & - & REF & - \\
\hline$\$ 38,000-\$ 47,999$ & $0.75(0.63-0.89)$ & 0.001 & $0.85(0.70-1.04)$ & 0.124 \\
\hline$\$ 48,000-\$ 62,999$ & $0.88(0.75-1.03)$ & 0.101 & $1.08(0.88-1.32)$ & 0.445 \\
\hline$\geq \$ 63,000$ & $0.81(0.70-0.94)$ & 0.007 & $1.04(0.83-1.31)$ & 0.721 \\
\hline \multicolumn{5}{|l|}{ Insurance status } \\
\hline Not insured & $4.56(3.77-5.52)$ & $<0.001$ & $3.79(2.98-4.82)$ & $<0.001$ \\
\hline Private & REF & - & REF & - \\
\hline Medicaid & $2.16(1.78-2.61)$ & $<0.001$ & $2.06(1.61-2.64)$ & $<0.001$ \\
\hline Medicare & $2.83(2.53-3.16)$ & $<0.001$ & $1.29(1.09-1.52)$ & 0.003 \\
\hline Other government & $1.65(1.05-2.58)$ & 0.027 & $1.30(0.73-2.32)$ & 0.367 \\
\hline Unknown & $3.64(2.87-4.62)$ & $<0.001$ & $2.62(1.96-3.51)$ & $<0.001$ \\
\hline \multicolumn{5}{|l|}{ Race } \\
\hline White & REF & - & REF & - \\
\hline Black & $2.13(1.82-2.49)$ & $<0.001$ & $2.08(1.73-2.50)$ & $<0.001$ \\
\hline Asian & $2.10(1.73-2.55)$ & $<0.001$ & $1.98(1.56-2.52)$ & $<0.001$ \\
\hline Hispanic & $1.44(1.24-1.66)$ & $<0.001$ & $1.45(1.22-1.72)$ & $<0.001$ \\
\hline Other & $1.64(1.30-2.06)$ & $<0.001$ & $1.70(1.28-2.26)$ & $<0.001$ \\
\hline \multicolumn{5}{|l|}{$\%$ No HSD } \\
\hline$\geq 21 \%$ & REF & - & REF & - \\
\hline $13-21 \%$ & $0.82(0.70-0.86)$ & 0.012 & $1.03(0.44-1.25)$ & 0.739 \\
\hline $7-12.9 \%$ & $0.78(0.68-0.91)$ & 0.001 & $1.03(0.84-1.26)$ & 0.803 \\
\hline$<7 \%$ & $0.81(0.70-0.95)$ & 0.007 & $1.21(0.96-1.52)$ & 0.112 \\
\hline \multicolumn{5}{|l|}{ Facility type } \\
\hline Community Cancer Program & $1.73(1.46-2.06)$ & $<0.001$ & $1.59(1.30-1.93)$ & $<0.001$ \\
\hline $\begin{array}{l}\text { Comprehensive Community } \\
\text { Cancer Program }\end{array}$ & $0.82(0.73-0.93)$ & 0.002 & $0.83(0.72-0.96)$ & 0.011 \\
\hline Academic Research Program & REF & - & REF & - \\
\hline $\begin{array}{l}\text { Integrated Network Cancer } \\
\text { Program }\end{array}$ & $0.67(0.52-0.86)$ & & $0.70(0.54-0.91)$ & 0.007 \\
\hline \multicolumn{5}{|l|}{ Stage (TNM) } \\
\hline I & REF & - & REF & - \\
\hline II & $1.58(1.29-1.92)$ & $<0.001$ & $1.33(1.06-1.66)$ & 0.012 \\
\hline III & $1.25(0.98-1.60)$ & 0.074 & $0.88(0.68-1.16)$ & 0.169 \\
\hline IV & $5.12(3.36-7.82)$ & $<0.001$ & $2.33(1.48-3.66)$ & $<0.001$ \\
\hline IVa & $3.50(2.77-4.41)$ & $<0.001$ & $2.38(1.84-3.08)$ & $<0.001$ \\
\hline $\mathrm{IVb}$ & $7.57(5.46-10.50)$ & $<0.001$ & $3.45(2.41-4.94)$ & $<0.001$ \\
\hline IVc & $8.52(6.92-10.50)$ & $<0.001$ & $3.98(3.11-5.09)$ & $<0.001$ \\
\hline NR & $1.46(1.29-1.64)$ & $<0.001$ & $1.38(1.19-1.60)$ & $<0.001$ \\
\hline \multicolumn{5}{|l|}{ Histology } \\
\hline PTC & $0.52(0.46-0.58)$ & $<0.001$ & $0.81(0.70-0.93)$ & 0.003 \\
\hline $\mathrm{HCC}$ & $1.00(0.72-1.37)$ & 0.984 & - & - \\
\hline FTC & $1.00(0.80-1.24)$ & 0.977 & - & - \\
\hline MTC & $1.17(0.83-1.65)$ & 0.359 & - & - \\
\hline \multicolumn{5}{|l|}{ Charlson-Deyo score } \\
\hline 0 & REF & - & REF & - \\
\hline 1 & $0.77(0.66-0.91)$ & 0.002 & $0.64(0.54-0.77)$ & $<0.001$ \\
\hline 2 & $1.93(1.54-2.43)$ & $<0.001$ & $1.19(0.93-1.52)$ & 0.165 \\
\hline Procedures per year per facility & $0.997(0.997-0.998)$ & $<0.001$ & $0.998(0.997-0.999)$ & 0.004 \\
\hline
\end{tabular}




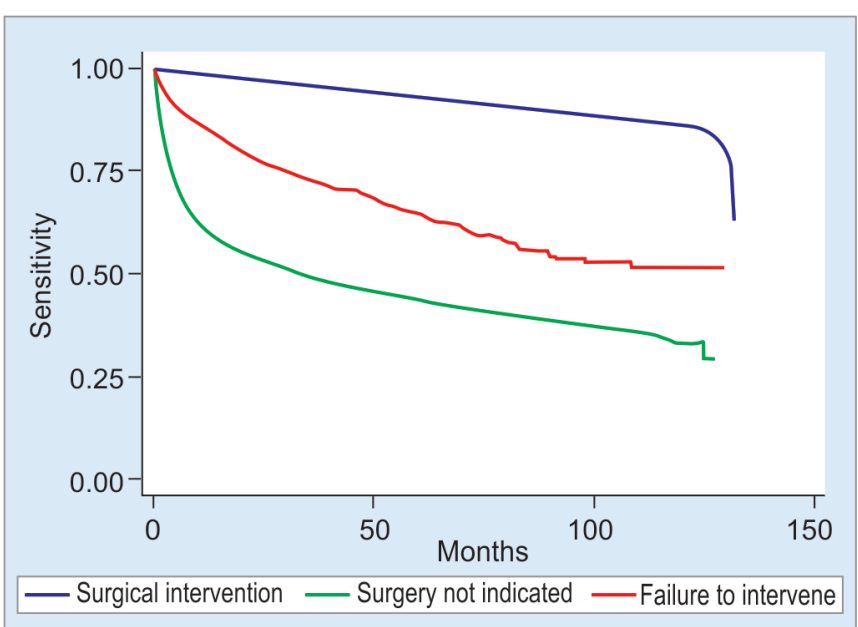

Fig. 1: Kaplan-Meier overall survival curves demonstrating significantly improved survival for those patients undergoing surgical resection as compared to those in the no surgery: intentional group [univariable cox hazard ratio $=16.095 \% \mathrm{Cl}(15.5-16.6), p<0.001$; multivariable cox hazard ratio $=3.995 \% \mathrm{Cl}(3.7-4.1), p<0.001]$ as well as those in the failure to intervene group [univariable cox hazard ratio $=7.195 \% \mathrm{Cl}(6.4-7.9)$, $p<0.001$; multivariable cox hazard ratio $=2.695 \% \mathrm{Cl}(2.4-2.9), p<0.001]$

community centers acting as a risk factor for $\mathrm{FTI}[\mathrm{OR}=1.7395 \% \mathrm{Cl}$ (1.46-2.06), $p<0.001]$ while higher volume centers were less likely to fail to intervene $(p<0.001)$ (Table 3$)$.

The effect of surgical intervention in thyroid cancer on survival is summarized in Figure 1. We see that undergoing thyroidectomy for treatment of thyroid cancer greatly improves patient survival. For those in whom surgery was intentionally not performed (NSI), survival was significantly worse [Univariable Cox Hazard Ratio $=16.0$ $95 \% \mathrm{Cl}$ (15.5-16.6), $p<0.001$; Multivariable Cox Hazard Ratio = 3.9 $95 \% \mathrm{Cl}(3.7-4.1), p<0.001]$. The FTI group had worse survival than the surgery group, but better survival than the NSI group [Univariable Cox Hazard Ratio $=7.195 \% \mathrm{Cl}(6.4-7.9), p<0.001$; Multivariable Cox Hazard Ratio $=$ Ratio $=2.695 \% \mathrm{Cl}(2.4-2.9), p<0.001]$.

\section{Discussion}

In this study, we found that being uninsured, being non-white race, and being male, are independent risk factors for FTI on thyroid cancer. These patients had a worse overall survival than those who underwent the appropriate thyroidectomy, but a better overall survival than those who were intentionally not operated upon. This suggests that performing thyroidectomy for thyroid cancer in patients who have an indication and are fit to undergo surgery improves their overall survival.

Recognizing that there is a superior overall survival in the surgical group, it is important to have an understanding of the demographics of the patients at risk for FTI when they present to the clinic. Doing so will optimize likelihood for follow-through. In the group studied, being non-white was a risk factor for FTI. It is well understood that minorities with thyroid disease present with more advanced disease than their nonminority counterparts, and are found to have a higher likelihood of intra and postoperative complications. ${ }^{5}$ Because of this advanced disease, surgeons with low volume or less experience may be less enthusiastic to operate on this cohort, thus increasing the chance that they have ultimate failure to intervention. Interestingly, the thyroid surgeons with the highest volumes (> 100 cases/year) have the lowest incidence of postoperative complications and death, but only do $5 \%$ of surgeries. ${ }^{6}$ If these patients who present with more advanced disease were to see a high volume surgeon, potentially they would be more likely to have surgery, and, thus, better survival. As it is now, $90 \%$ of patients operated upon by high volume surgeons are Caucasian, and, although the incidence of thyroid cancer is highest in Caucasians (14.3/100,000 persons), this group does not represent $90 \%$ of all diagnoses (Black $8 / 100,000$ persons, Asian/Pacific Islander 13.2/100,000 persons, American Indian/Alaska Native 8.5/100,000 persons) (SEER 2015).

Having nonprivate insurance is a risk factor for FTI. The potential for high out-of-pocket expenses for those who are uninsured and concerns for variability in reimbursement likely deter both patients and surgeons when has Medicare. Inadequate treatment and worse overall survival in those cancer patients who are uninsured is not surprising, nor is it a novel discovery. Previous reports utilizing the SEER database demonstrated on a large scale that in the 10 most deadly cancers, the patients without insurance were more likely to present with advanced-stage disease, were less likely to undergo cancer-directed surgery, and had worse survival. ${ }^{7}$ There are some emerging studies that have reviewed the implementation of the Massachusetts health care reform as it relates to improving rates of resection for pancreatic cancer patients. ${ }^{7}$ Although it is not known if the increased rates of resection identified in the Massachusetts health care reform will be mimicked on a larger scale with any potential change in the structure of the United States healthcare system, but it is certainly encouraging to think that broadening insurance coverage has the potential to positively influence overall survival of thyroid and other cancers nationwide.

This study has multiple limitations. Firstly, in utilizing a large national dataset, such as the NCDB, there are inherent limitations in the data's retrospective nature and secondary source. ${ }^{8,9}$ Moreover, categorization for patients as FTI may at times be inappropriate as granular details may be lost in abstracting large volumes of data. Finally, disease-specific survival and recurrence is not available through the NCDB. While this is a well described limitation, it is particularly significant in malignancies with excellent overall survival, such as thyroid cancer.

There are multiple considerations when identifying appropriate patients for thyroidectomy. When thyroid cancer is identified, the size of the mass, the age and comorbidities of the patient, and the cytology of the tumor all play a role in the decision of whether or not to operate. If there is considered no reason not to operate, surgical intervention improves overall survival and FTI is suboptimal patient care. In spite of the limitations of this study, there is a clear group of patients that is in need of closer attention and follow-up whose survival is compromised by FTI.

\section{Conclusion}

Thyroidectomy is the appropriate management for most patients with thyroid cancer. Those who undergo thyroidectomy for their cancer have the best survival. Not surprisingly, those who make the decision with their physician to not have surgery, whether it be because of high risk comorbidities, or because of advanced age and the likelihood that surgery will not be of benefit, have the lowest rates of survival. Between these groups, there is the FTI group; those who have an indication for surgery, but who do not undergo an operation. The FTI group is more likely to have Medicare, be non-white, and be male, and their overall survivor is worse than those people who did undergo surgical intervention. Recognizing the demographics 
of this population and being cognizant of their presentation in the clinic can potentially increase the likelihood that we take action and make an effort to intervene, and improve their overall survival as a result.

\section{References}

1. Bilimoria $\mathrm{KY}$, Bentrem DJ, Ko $\mathrm{CY}$, et al. National failure to operate on early stage pancreatic cancer. Ann Surg 246 2007;(2):173-180. DOI: 10.1097/SLA.0b013e3180691579

2. Conlon KC, Klimstra DS, Brennan MF. Long-term survival after curative resection for pancreatic ductal adenocarcinoma. Clinicopathologic analysis of 5-year survivors. Ann Surg 1996;223(3):273-279 DOI: 10.1097/00000658-199603000-00007

3. Endorsement Summary: Cancer Measures. October 23, 2012. National Quality Forum. Washington, DC

4. StataCorp. Stata Statistical Software: Release 13. College Station, TX: StataCorp LP; 2013.
5. Loyo M,Tufano RP, Gourin CG. National trends in thyroid surgery and the effect of volume on short-term outcomes. Laryngoscope 2013;123(8):2056-2063. DOI: 10.1002/lary.23923

6. Sosa JA, Mehta PJ, Wang TS, et al. Racial disparities in clinical and economic outcomes from thyroidectomy. Ann Surg 2007;246(6): 1083-1091. DOI: 10.1097/sla.0b013e31812eecc4

7. Walker GV, Grant SR, Guadagnolo BA, et al. Disparities in stage at diagnosis, treatment, and survival in nonelderly adult patients with cancer according to insurance status. J Clin Oncol 2014;32(28): 3118-3125. DOI: 10.1200/JCO.2014.55.6258

8. Loehrer AP, Chang DC, Hutter MM, et al. Health insurance expansion and treatment of pancreatic cancer: does increased access lead to improved care? J Am Coll Surg 2015;221(6):1015-1022. DOI: 10.1016/j. jamcollsurg.2015.09.010

9. Bilimoria KY, Stewart AK, Winchester DP, et al. The National Cancer Data Base: a powerful initiative to improve cancer care in the United States. Ann Surg Oncol 2008;15(3):683-690. DOI: 10.1245/s10434007-9747-3 